\title{
The immune suppressive effect of dexamethasone in rheumatoid arthritis is accompanied by upregulation of interleukin 10 and by differential changes in interferon $\gamma$ and interleukin 4 production
}

Catharina M Verhoef, Joel A G van Roon, Marieke E Vianen, Floris P J G Lafeber, Johannes W J Bijlsma

\begin{abstract}
Objectives-The influence of dexamethasone on interleukin 10 (IL10) production and the type 1 (T1)/type 2 (T2) T cell balance found in rheumatoid arthritis (RA) was studied.

Methods-Peripheral blood mononuclear cells (PB MNC) were isolated from 14 RA patients both before and 7 and 42 days after high dose dexamethasone pulse therapy. The ex vivo production of IL10, interferon $\gamma$ (IFN $\gamma$ ) (T1 cell), and IL4 (T2 cell) by PB MNCs was assessed, along with parameters of disease activity (erythrocyte sedimentation rate, $\mathrm{C}$ reactive protein, Visual Analogue Scale, Thompson joint score). In addition, the in vitro effect of dexamethasone $(0.02,0.2$, and $2 \mu \mathrm{M})$ on PB MNC IL10, IFN $\gamma$, and IL4 production was studied.
\end{abstract}

Results-Dexamethasone pulse therapy resulted in a rapid and sustained decrease in RA disease activity. IL10 production increased after dexamethasone treatment and this was sustained for at least six weeks. A transient strong decrease in IFN $\gamma$ was seen shortly after corticosteroid treatment, while IL4 only decreased slightly. This led to an increased IL-4/IFN $\gamma$ ratio. In vitro, IL10 production was not detectable, IFN $\gamma$ and IL4 decreased, but the effect was more pronounced for IFN $\gamma$ than for IL4, which again resulted in an increased IL $4 /$ IFN $\gamma$ ratio.

Conclusion-Dexamethasone therapy in RA patients leads to a rapid, clinically beneficial effect. The upregulation of IL10 production may be involved in the prolonged clinical benefit. The strong immunosuppressive effect is most evident in the decrease in IFN $\gamma$, and is therefore accompanied by a relative shift towards $\mathrm{T} 2$ cell activity. In vitro evaluation showed that this shift in $T$ cell balance was a direct effect of dexamethasone and thus independent of the hypothalamic-pituitaryadrenal axis.

(Ann Rheum Dis 1999;58:49-54)

At least two types of $\mathrm{T}$ cells have been defined on the basis of their specific cytokine profiles. ${ }^{1}$ $\mathrm{T} 1$ cells participate in cytotoxic responses and delayed type hypersensitivity reactions and they specifically produce interferon $\gamma$ (IFN $\gamma$ ) and stimulate macrophages to produce proinflammatory cytokines such as interleukin (IL) 1 and tumour necrosis factor $\alpha(\mathrm{TNF} \alpha){ }^{2}$ These cytokines are involved in the cartilage degradation and bone erosion associated with rheumatoid arthritis (RA)..$^{3-5}$ T2 cells specifically produce IL4, which has inhibitory effects on monocytes/macrophages and helps B cells to differentiate into immunoglobulin (IgE) producing cells. ${ }^{1} \mathrm{~T} 1$ and $\mathrm{T} 2$ cells are known to counterbalance each other. ${ }^{12}$ It has been suggested that an imbalance between $\mathrm{T} 1$ and T2 cell activity contributes to a number of autoimmune disorders, including RA. Although $\mathrm{T}$ cell activity in general seems low in the RA joint, several studies have shown a relative predominance of $\mathrm{T} 1$ over T2 cell activity. ${ }^{56}$ It has further been suggested that this relative increase in T1 cell activity in RA joints plays a part in $\mathrm{T}$ cell driven joint destruction.

The suggestion has been made that IL 4 production in RA joints is defective. Human and animal in vitro experiments have shown that $\mathrm{T} 1$ cell induced joint inflammation, and hence damage to articular cartilage, can be inhibited by adding the $\mathrm{T} 2$ cell cytokine IL4. ${ }^{7-9}$ In support of this finding, we found that the prevalence of hayfever (an IL4 mediated disorder) is lower in RA patients than in a control population, and that RA patients with hayfever showed less disease activity than matched RA patients without hayfever. ${ }^{10}$

IL10 is a polyfunctional cytokine produced by $\mathrm{T}$ cells, macrophages/monocytes, and $\mathrm{B}$ cells. Its presence in RA peripheral blood and synovial tissue (demonstrated by RT-PCR of fresh frozen biopsy specimens) has been reported. ${ }^{11}{ }^{12}$ The fact that both RA serum and RA synovial fluid contains significantly more IL10 than that of normal subjects underlines its role in the pathogenesis of RA. ${ }^{13}$ IL 10 has been shown to down regulate a number of macrophage functions, including the production of IL1 $\beta$, IL6, and TNF $\alpha$. Moreover, IL10 induces the production of endogenous TNF inhibitors such as soluble TNF receptors and down regulates TNF receptor expression. ${ }^{11}$ IL10 also participates in immunoregulation by stimulating the proliferation and differentiation of B cells. ${ }^{14}$ Nevertheless, several human in vitro and animal ex vivo experiments have
Accepted for publication 8 October 1998 
Table 1 Patient characteristics

\begin{tabular}{lll}
\hline & $R A$ pulse $(n=14)$ & RA control $(n=7)$ \\
\hline Mean disease duration in years (range) & $14(2-39)$ & $12(4-33)$ \\
Mean age in years (range) & $58.6(41-76)$ & $65(54-73)$ \\
Male/female & $4 / 10$ & $3 / 4$ \\
ACR functional class 1/2/3 & $0 / 12 / 0$ & $2 / 4 / 1$ \\
Mean (SD) ESR (mm 1st h) & $70(28)$ & $38(38)$ \\
Mean (SD) CRP (mg/l) & $61(30)$ & $22(20)$ \\
DMARD medication & 7 & 3 \\
$\quad$ methotrexate & 2 & \\
parenteral gold & 1 & 2 \\
OH-chloroquine & 1 & 1 \\
$\quad$ sulphasalazine & 1 & 1 \\
azathioprine & 3 &
\end{tabular}

Characteristics of 14 RA patients with active disease (before receiving dexamethasone pulse therapy) and seven randomly selected RA patients (RA control) with less active disease and not considered for dexamethasone pulse therapy.

demonstrated the strong immunosuppressive effect of IL10 on T cell mediated inflammation, and this has now been succesfully tested in RA. ${ }^{12} 15$

Glucocorticosteroids are widely used because of their immunosuppressive and antiinflammatory properties and have been used to treat patients with active RA for nearly 50 years. The beneficial clinical effects of both low dose and high dose glucocorticosteroid treatment are well known. Treatment of treatment resistant RA with intravenous high dose dexamethasone pulse therapy is usually effective in suppressing the symptoms of severe inflammation. ${ }^{16-18}$

Glucocorticosteroids suppress a wide variety of non-specific inflammatory responses and specific immunological processes. Little is known, however, about the exact mechanisms by which they act in RA patients. Several studies have shown glucocorticosteroids to have indirect inhibitory effects on the immune system, mediated by the hypothalamicpituitary-adrenal axis and stress responses. ${ }^{19} 20$ Glucocorticosteroids have also been shown to act directly on leucocytes by inhibiting cytokines produced by monocytes, macrophages, and T cells. ${ }^{21-23}$ Suppression of IL2 and IFN $\gamma$ mRNA by glucocorticosteroids has been documented, along with suppression of $\mathrm{TNF} \alpha$ expression in synovial fluid and synovial tissue shortly after methylprednisolone pulse therapy. ${ }^{24}{ }^{25}$ It has been shown in vitro that glucocorticosteroids inhibit proliferative responses of T cells to mitogens and antigens. On the other hand, it is possible that part of the immunosuppressive effect of glucocorticosteroids is mediated by upregulating the production of immunosuppressive cytokines such as IL $10 .{ }^{26}$ Pretreatment with glucocorticosteroids of patients undergoing cardiopulmonary bypass (which induces major inflammatory activity) resulted in markedly increased IL10 concentrations and decreased concentrations of TNF $\alpha$ and IL8. ${ }^{27}$ Moreover, glucocorticosteroids may have differential suppressive effects on $\mathrm{T}$ cell sub-populations and could thereby affect the balance between $\mathrm{T} 1$ and $\mathrm{T} 2$ cell activity. ${ }^{21} 24^{2628-31}$ It has been shown in vitro that dexamethasone can completely inhibit IFN $\gamma$ production in human lymphocytes while priming the cells to produce a Th2 cytokine response that includes induction of IL4, IL10, and IL13. ${ }^{32}$

This study was designed to evaluate the effects of dexamethasone on T1 and T2 T cell activity and IFN $\gamma$ and IL 4 production in relation to RA disease activity parameters. In addition, IL10 was monitored to study its role in the immunosuppressive effect of glucocorticosteroids. To see whether dexamethasone directly affects $\mathrm{T}$ cell cytokine production, bypassing the hypothalamic-pitituitary-adrenal axis and stress responses, the effect of dexamethasone on RA peripheral blood mononuclear cells (PB MNC) was tested in vitro.

\section{Methods}

We studied 14 RA patients with active disease who had been admitted for high dose intravenous (iv) dexamethasone pulse therapy as part of their treatment strategy. Table 1 gives the patient characteristics. The diagnosis of RA was based on the 1987 revised ACR criteria. Twelve patients were positive for rheumatoid factor and had erosive disease. None of the patients were using oral glucocorticosteroid therapy at the time of the study. Five patients had used glucocorticosteroids before, but not during, the preceding three months. Disease modifying anti-rheumatic drug (DMARD) medication was not changed between day 0 and day 7. At day 42, the DMARD medication of three patients was changed: two more patients were given methotrexate and one additional patient was switched to $\mathrm{OH}-$ chloroquine. Patients received $200 \mathrm{mg}$ dexamethasone iv on three alternating days. The disease activity parameters were determined before treatment (day 0), shortly after (day 7), and six weeks (day 42) after dexamethasone pulse therapy was given. RA disease activity was assessed by erythrocyte sedimentation rate (ESR, Westergren), C reactive protein (CRP), the Visual Analogue Scale (VAS), and the Thompson joint score (max score 534; all by the same observer). ${ }^{33}$ Functional class was determined according to the 1988 ACR criteria. ${ }^{34}$

The production of IL 4 and IFN $\gamma$ by T cells in an isolated peripheral blood (PB) mononuclear cell (MNC) population was evaluated at day 0 (before) and at days 7 and 42 after treatment. For this purpose, mononuclear cells were isolated from PB. PB was diluted 1:1 with Dulbeco's modified Eagle's medium (DMEM, Gibco 074-01600) and MNC isolated by density centrifugation using Ficoll-Paque (Pharmacia Biotech, Roosendaal, the Netherlands). Isolated cells $\left(5 \times 10^{5}\right.$ per $\left.\mathrm{ml}\right)$ were cultured for 48 hours in DMEM supplemented with PSG (penicilline $100 \mathrm{U} / \mathrm{ml}$, streptomycin sulphate $100 \mu \mathrm{g} / \mathrm{ml}$ and glutamine $2 \mathrm{mmol} / \mathrm{l}$ ) and $10 \%$ human adult male $\mathrm{AB}^{+}$serum. ${ }^{35}{ }^{36} \mathrm{IFN} \gamma$ and IL4 production were measured to separately assess, respectively, $\mathrm{T} 1$ and $\mathrm{T} 2$ cell activity. Because of the undetectably low spontaneous production of IFN $\gamma$ and IL4, the PB MNC were stimulated with a specific $\mathrm{T}$ cell stimulus: anti-CD3/anti-CD28 antibodies (CLB, Amsterdam, the Netherlands; both diluted $1: 1000) .^{35}{ }^{36}$ Interassay variation was less than 

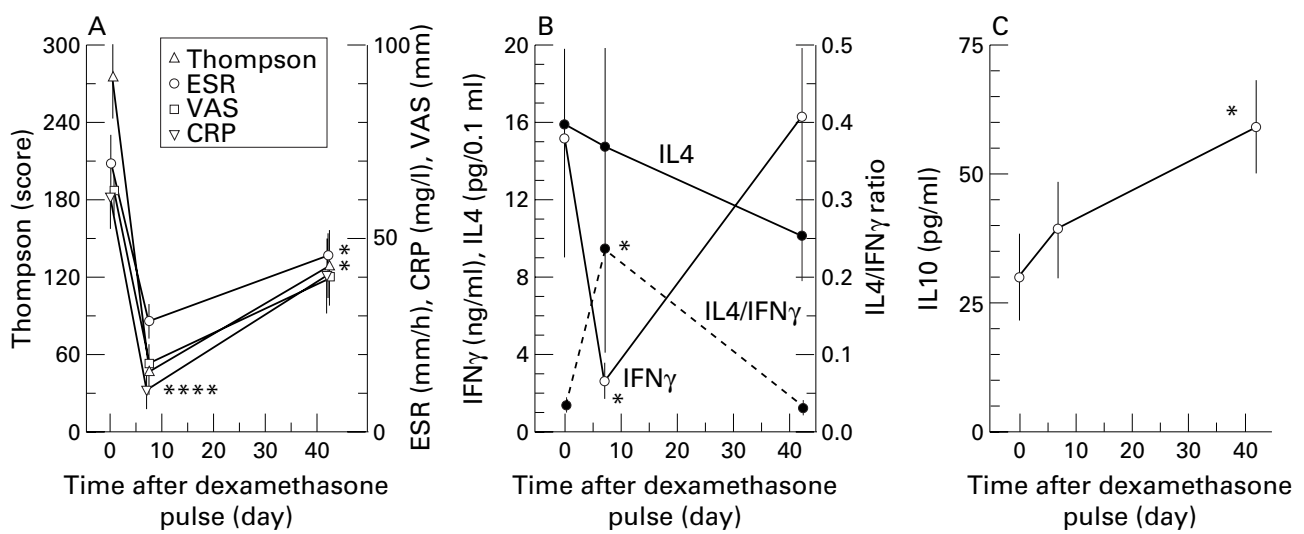

Figure 1 (A) RA disease activity; mean (SEM) values of Thompson joint score, erythrocyte sedimentation rate, $C$ reactive protein, and Visual Analogue Scale of $14 \mathrm{RA}$ patients with active disease are given. Patients received $200 \mathrm{mg}$ dexamethasone iv at day 1, 3, and 5. Asterisks indicate a statistical significant difference on day 7 and day 42 . (B) Ex vivo IFN $\gamma$ and IL4 production, as measures for T1 and T2 T cell activity respectively, of PB MNC of 14 RA patients who received $200 \mathrm{mg}$ dexamethasone iv at day 1,3, and 5. Mean (SEM) values are given. IFN $\gamma$ and IL4 are shown on the left axis and the average of the individual IL4/IFN $\gamma$ ratios on the right axis. Asterisks indicate a statistical significant difference on day 7. (C) Ex vivo measured IL10 production of PB MNC of 10 RA patients who received $200 \mathrm{mg}$ dexamethasone iv at day 1, 3, and 5. Mean (SEM) values are given. Asterisk indicates a statistical significant difference on day 42.

$6 \%$ and daily variation in blood sampling induced a variation of less than $11 \%$. The ratio of IL4 to IFN $\gamma$ production was calculated as a measure of differential $\mathrm{T}$ cell activity. In addition, the IL10 production of PB MNC was determined after 48 hours of culture. As IL10 is also produced in significant amounts by non- $T$ cells, and is in humans not discriminative for $\mathrm{T} 1$ or $\mathrm{T} 2$ cells, no $\mathrm{T}$ cell stimulus was used for this cytokine. After 48 hours, the culture media were harvested and rendered cell free by centrifugation, frozen in liquid nitrogen and stored at $-20^{\circ} \mathrm{C}$. IFN $\gamma$, IL 4 , and IL 10 concentrations were determined by ELISA according to the manufacturer's instructions (Medgenix, Flerus, Belgium). The detection limits of the assays were $5 \mathrm{pg} / \mathrm{ml}$ for IFN $\gamma$ and IL10 and $10 \mathrm{pg} / \mathrm{ml}$ for IL4.

IN VITRO EXPERIMENTS

Increasing concentrations of dexamethasone $(0,0.02,0.2,2 \mu \mathrm{M}$. $)$ were added to the PB MNCs of the 14 RA patients with active disease before dexamethasone pulse therapy. This concentration range corresponds with the plasma dexamethasone range measured shortly after pulse therapy (unpublished data). As a control, the same experiments were done on PB MNCs of seven randomly selected RA patients not considered for dexamethasone pulse therapy and with significantly less active disease (see table 1 for patient characteristics). The PB MNCs were cultured for 72 hours, after which the IFN $\gamma$, IL4, and IL10 concentrations were determined. With respect to IFN $\gamma$ and IL4 production during the last 48 hours, anti-CD3/anti-CD28 was added to increase the production of both of these cytokines in an aspecific manner. With respect to IL10, no additional stimulus was used.

Statistical analysis was performed using the Wilcoxon signed rank test and the MannWhitney $U$ test for comparisons between RA pulse patients and RA control patients. A value of $p<0.05$ was considered statistically significant.

\section{Results}

Figure 1 (A) shows the clinical effect of dexamethasone pulse therapy. Dexamethasone pulse therapy results in a fast and statistically significant $(p \leqslant 0.005)$ decrease in Thompson joint score, ESR, CRP, and VAS that lasted, although less significantly for at least six weeks (for Thompson joint score and ESR, $\mathrm{p}<0.005$; for CRP and VAS, $p=0.06$ and $p=0.07$, respectively).

Figure 1 (B) shows the changes in the PB MNC cytokine production of the $14 \mathrm{RA}$ patients receiving high dose glucocorticosteroid treatment. A statistically significant decrease in IFN $\gamma$ was seen directly after glucocorticosteroid treatment $(p \leqslant 0.05)$. Six weeks after treatment, IFN $\gamma$ production was no lower than before treatment. In contrast, IL4 production at day 7 and day 42 showed only a slight and statistically non-significant decrease $(p \leqslant 0.1)$. The IL4/IFN $\gamma$ ratios from these patients therefore showed a statistically significant increase $(p<0.005)$ shortly after glucocorticosteroid treatment, which suggests a change in differential $\mathrm{T}$ cell activity towards a relatively more pronounced T2 cell activity. This change in T cell balance returned to baseline after six weeks $(\mathrm{p} \leqslant 0.1)$.

On average there was an increase in spontaneous IL10 production that became statistically significant at day $42(\mathrm{p}<0.05)$ (fig 1$)$. This increase was found in 8 of 10 patients with detectable spontaneous IL10 production. In the remaining four patients IL10 was at all times below the ELISA detection limit.

To see whether the change in differential $\mathrm{T}$ cell activity was a direct effect of dexamethasone on inflammatory cells, PB MNCs were taken from the RA patients before dexamethasone pulse therapy and exposed to dexamethasone in vitro. A statistically significant and dose dependent decrease was seen for both IFN $\gamma$ and IL4 (fig 2 (A)) ( $\mathrm{p} \leqslant 0.05$ for both IFN $\gamma$ and IL4 at all concentrations of dexamethasone). This decrease was stronger for IFN $\gamma$ than for IL4. This resulted in a statistically significant, 

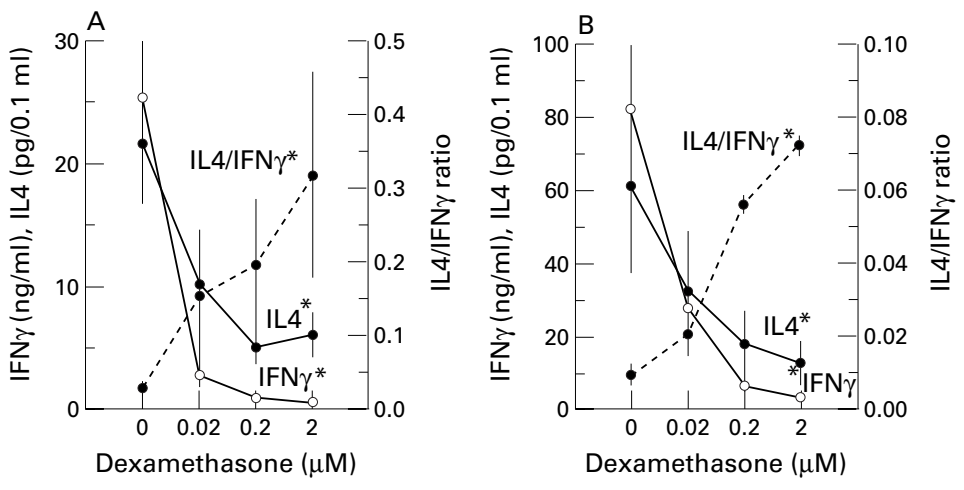

Figure 2 (A) In vitro IFN $\gamma$ and IL4 production, as measures for T1 and T2 T cell activity respectively, of $P B M N C$ obtained from $14 R A$ patients before dexamethasone pulse therapy, which in vitro have been exposed to dexamethasone. Mean (SEM) values are given. IFN $\gamma$ and IL4 are shown on the left axis and the average of the individual IL $4 / I F N \gamma$ ratios on the right axis. Asterisks indicate a statistical significant difference at all different dexamethasone concentrations. (B) In vitro IFN $\gamma$ and IL 4 production, as measure for T1 and T2 T cell activity respectively, of $P B M N C$ of seven randomly selected $R A$ patients, in vitro exposed to dexamethasone. Mean (SEM) values are given. IFN $\gamma$ and IL4 are shown on the left axis and the average of the individual IL4/IFN $\gamma$ ratios on the right axis. Asterisks indicate a statistical significant difference at all dexamethasone concentrations.

dose dependent increase in the mean IL4 to IFN $\gamma$ ratio $(p \leqslant 0.05$ at all concentrations of dexamethasone tested). The relative increase in T2 cell activity was in accordance with the results of the differential $\mathrm{T}$ cell activity measured ex vivo shortly after dexamethasone pulse therapy.

No spontaneous IL10 production could be detected after adding dexamethasone in vitro to PB MNCs taken from RA patients before dexamethasone pulse therapy.

To see whether the in vitro effect of glucocorticosteroids on the MNCs was related to the disease activity in the RA patients, this effect was measured for 14 RA patients receiving dexamethasone treatment (with high disease activity) and seven randomly selected RA patients who had not been given dexamethasone pulse therapy (RA controls). Table 1 shows the characteristics of both groups. There was no between group difference in mean disease duration or mean age. As expected, the ESR and CRP levels were lower in the randomly selected RA control group. The cytokine profiles of these patients showed a similar pattern (fig 2 (B)). After adding dexamethasone, IFN $\gamma$ decreased more sharply than IL4, also for the RA patients with relatively mild disease. There was thus an increase in the ratio of IL4 to IFN $\gamma$. Interestingly, baseline IL 4 and IFN $\gamma$ production by PB MNCs of the patients with lower RA disease activity was higher than the corresponding cytokine production of RA patients with active disease, who had been admitted for glucocorticosteroid pulse therapy $(\mathrm{p}<0.05$ for both IFN $\gamma$ and IL4). However, IL4/IFN $\gamma$ ratio of these RA control patients did not differ significantly from the baseline levels of RA patients receiving dexamethasone pulse therapy. In vitro IL10 production by PB MNCs cultured with or without dexamethasone was below the detection limit for the RA control patients as well.

\section{Discussion}

In chronic RA, proinflammatory cytokine production by macrophages is involved in joint destruction and contributes to systemic disease parameters, such as CRP and ESR. This increased macrophage activity in the joints of RA patients is, it has been suggested, controlled by $\mathrm{T}$ cell activity. The balance between $\mathrm{T} 1$ and T2 cell activity seems crucial in controlling the proinflammatory immune response. Stimulation of T2 cell activity might therefore ameliorate RA disease activity, either directly by inhibition of macrophage activity or indirectly by suppression of $\mathrm{T} 1$ cells. The latter has been shown by many in vitro and human and animal in vivo studies and has also been suggested by some clinical studies. ${ }^{7910}$ As glucocorticosteroid therapy has been proved effective in reducing symptoms of inflammation in RA, we hypothesised that this effect may, apart from immunosuppression, be caused by differential suppression of $\mathrm{T} 1$ cell activity, leaving relatively increased $\mathrm{T} 2$ cell activity.

In accordance with previous studies, we were able to observe a fast, relatively longlasting albeit declining, clinical response to dexamethasone pulse therapy in patients with RA.

Interestingly, we found increased IL10 production after dexamethasone pulse therapy. As IL10 is known to be an inhibitor of proinflammatory cytokines, it is possible that the beneficial effect of dexamethasone is partly caused by upregulation of IL10 producing cells. The source of IL10 remains uncertain. IL10 is produced by both $\mathrm{T} 1$ and $\mathrm{T} 2$ cells and for a significant part produced by monocytes/ macrophages and B cells. This is in contrast with mice where IL 10 is more clearly a T 2 cell cytokine. The fact that we did not find stimulated IL10 production in the in vitro experiments corroborates previous studies where it was only after restimulation of leucocytes, cultured for one week in the presence of dexamethasone, that significant IL10 mRNA production was observed..$^{32}$ In the ex vivo experiments, patients received high dose dexamethasone pulses and the observed increased IL10 production at day 42 points to a slow but relatively longlasting immunoregulatory effect. Based on these data it might be expected that RA patients with low disease activity have higher IL10 concentrations. Nevertheless, a correlation between IL10 concentration and disease activity in RA patients has not been reported yet. Synergism between upregulation of IL10 and the additional effect of corticosteroids may be responsible for the clinical effect.

In this study, IFN $\gamma$ and IL4 production were used to indicate respectively, T1 and T2 cell activity. A statistically significant decrease in T1 cell activity was seen soon after dexamethasone pulse therapy was given. As no effect on T2 cell cytokine production was observed, the $\mathrm{T}$ cell balance shifted towards $\mathrm{T} 2$ cell activity. This relatively greater sensitivity of IFN $\gamma$ producing cells to the immunosuppressive effects of glucocorticosteroids, compared with IL4 producing cells, has also been reported by Zieg et al. ${ }^{37}$ The change in T1/T2 cell balance 
at day 7 had disappeared at day 42 . This is probably caused by the fast decline in plasma dexamethasone concentration after infusion; high concentrations were found around day 7 at levels about $100-1000 \mathrm{nM}$, levelling off at day 42 to about $1 \mathrm{nM}$ (unpublished data).

As has been shown previously, dexamethasone specifically inhibits the levels of mRNA for both IL2 and IFN $\gamma$ in normal human lymphocytes. ${ }^{25}$ Murine $\mathrm{T}$ cell growth factors IL2 and IL4 production is differentially regulated by glucocorticoids, presumably through their capacity to bind with steroid receptors in lymphocytes and to increase or repress the production of cytokines selectively. ${ }^{24}$ Other investigators reported on the ability of glucocorticosteroids to suppress the production of IL2 by inhibiting IL2 gene transcription. ${ }^{38}$

A similar effect, as observed ex vivo on $\mathrm{T}$ cell balance, was seen after adding dexamethasone in vitro to the PB MNCs of the RA patients (considered for glucocorticosteroid pulse therapy) and also on PB MNCs of randomly selected RA patients. The dexamethasone concentrations used for the in vitro experiments correspond with the relatively high dexamethasone serum concentrations measured shortly after dexamethasone pulse therapy (unpublished data). These results suggest that dexamethasone has a direct effect on PB MNCs (including $\mathrm{T}$ cells as well as monocytes/ macrophages) and also show that the effect is not influenced by disease activity and does not necessarily involve an indirect effect via the hypothalamic-pituitary-adrenal axis and stress responses. This does not exclude that in addition to this direct effect of dexamethasone on leucocytes dexamethasone influences disease activity and by that induces changes that are of influence on differential $\mathrm{T}$ cell activity. In this respect changes in adhesion molecule expression ${ }^{39}$ should be taken into account.

The observed lower IFN $\gamma$ and IL4 production of RA patients with high disease activity seems confusing in the light of the supposedly dominant $\mathrm{T} 1$ cell activity in RA. However, peripheral inhibition of $\mathrm{T}$ cell cytokines by intra-articularly produced suppressive cytokines (regarded as local counter-mechanism to joint inflammation), such as TGF $\beta$ or IL10, leaking into the circulation where the trigger for the immunological response is absent, or selective migration of $\mathrm{T} 1$ cells into the joint might explain this finding. ${ }^{8}$

In summary, this study demonstrates that the quick acting and clinically beneficial effect of dexamethasone pulse therapy in RA patients is immunosuppressive in nature. Upregulation of IL10 production may contribute to this relatively prolonged immunosuppressive effect of dexamethasone pulse therapy. The effect is accompanied by a shift in $\mathrm{T}$ cell balance towards relatively increased $\mathrm{T} 2$ cell activity. This effect of dexamethasone on $\mathrm{T}$ cell balance is thought to be a direct effect of glucocorticosteroids on these cells, independent of the hypothalamic-pituitary-adrenal axis.
We thank the patients for their collaboration and also the physicians who put forward patients for this study: Dr J W G Jacobs, Dr A A Kruize, Dr A A M Blaauw, C A Goldhoorn, H M Hulsmans, R M van Vugt, Dr M J van der Veen.

Funding: this work was supported by the "Nationaal Reumafonds" (Dutch League against Rheumatism), the Netherlands.

1 Romagnani S. Biology of human Th1 and Th2 cells. J Clin Immunol 1995;15:121-9.

2 Mosmann TR, Sad S. The expanding universe of T cell subsets: Th1, Th2 and more. Immumol Today 1996;17: $138-46$

3 Wilbrink B, Holewijn M, Bijlsma JWJ, Van Roy JCAM, Den Otter W, Van Eden W. Suppression of human cartilage proteoglycan synthesis by rheumatoid synovial fluid mononuclear cells activated with mycobacterial $60 \mathrm{kd}$ heat shock protein. Arthritis Rheum 1993:36:514-18.

4 Schulze-Koops H, Lipsky PE, Kavanaugh AF, David LS. Elevated Th1- or Th0- like cytokine mRNA in peripheral circulation of patients with rheumatoid arthritis. J Immunol 1995;155:5029-37.

5 Dolhain RJEM, Van Der Heiden AN, Ter Haar NT, Breedveld FC, Miltenburg AMM. Shift towards T lymphocytes with a T helper 1 cytokine-secretion profile in the joints of with a Thelper 1 cytokine-secretion profile in the joints of 39:1961-9.

6 Panayi GS, Lanchbury JS, Kingsley GH. The importance of the $T$ cell in initiating and maintaining the chronic synoviits of rheumatoid arthritis. Arthritis Rheum 1992;35:72935.

7 Van Roon JAG, Van Roy JLAM, Gmelig-Meyling FHJ, Lafeber FPJG, Bijlsma JWJ. Prevention and reversal of cartilage degradation in rheumatoid arthritis by interleukin-10 and interleukin-4. Arthritis Rheum 1996;39:829-35.

8 Van Roon JAG, Verhoef CM, Gmelig-Meyling FHJ, Lafeber FPJG, Bijlsma JWJ. Peripheral type $1 /$ type $2 \mathrm{~T}$ cell cytokine production in RA correlates with erythrocyte sedimentation rate and radiog

9 Joosten LAB, Lubberts E, Durez P, Helsen MMA, Jacobs MJM, Goldman M, et al. The role of IL-4 and IL-10 in the regulation of murine collagen induced arthritis. Arthritis regulation of murine collag

10 Verhoef CM, Van Roon JAG, Vianen ME, BruinzeelKoomen CAFM, Lafeber FPJG, Bijlsma JWJ. Mutual antagonism of rheumatoid arthritis and hayfever; a role for type $1 /$ type $2 \mathrm{~T}$ cell balance. Ann Rheum Dis 1998;57:275-80.

11 Feldmann M, Brennan FM, Maini RN. Role of cytokines in rheumatoid arthritis. Annu Rev Immunol 1996;14:397440 .

12 Katsikis PD, Chu CQ, Brennan FB, Maini RN, Feldmann $M$. Immunoregulatory role of interleukin 10 (IL-10) in rheumatoid arthritis. J Exp Med 1994;179:1517-27.

13 Cush JJ, Splawski JB, Thomas R, McFarlin JE, SchulzeKoops H, Davis LS, et al. Elevated Interleukin-10 levels in patients with rheumatoid arthritis. Arthtritis Rheum 1995; 38:96-104.

14 Rousset F, Garcia E, Deference T, Peronne C, Vezzio N, Hsu DH, et al. IL-10 is a potent growth and differentiation factor for activated human B lymphocytes. Proc Natl Acad Sci 1994;89:1890-3.

15 Maini RN, Paulus H, Breedveld FC, Moreland LW, William St Clair E, et al. rhulL-10 in subjects with active rheumatoid arthritis (RA): a phase 1 and cytokine study. rheumatoid arthritis (RA): a phas
Arthritis Rheum 1997;40:S224.

16 Bijlsma JWJ, Van Everdingen AA, Jacobs JWG. Corticosteroids in rheumatoid arthritis. How best to use them? Clin Immunother 1995;4:271-86.

17 Smith MD, Ahern MJ, Roberts-Thompson PJ. Pulse methylprednisolone therapy in rheumatoid arthritis: Unproved therapy, unjustified therapy, or effective adjunctive treatment? Ann Rheum Dis 1990;49:265-7.

18 Weusten BCAM, Jacobs JWG, Bijlsma JWJ. Short-term and long-term complications of corticosteroid pulse therapy in rheumatoid arthritis. Semin Arthritis Rheum 1993;23. 183-92.

19 Harbuz MS, Stephanou A, Sarlis N, Lightman SL. The effect of recombinant human interleukin (IL)- $1 \alpha$, IL- $1 \beta$ or IL-6 on hypothalamo-pituitary-adrenal axis activation. J Endocrinol 1992;133:349-55.

20 Lyson K, McCann SM. The effect of Interleukin-6 on pituitary hormone release in vivo and in vitro. Neuroendocrinology 1992;54:262-6.

21 Norbiato G, Bevilacqua M, Vago T, Lerici M. Glucocorticoids and Th-1, Th-2 type cytokines in rheumatoid arthritis, osteoarthritis, asthma, atopic dermatitis and AIDS. Clin Exp Rheumatatol 1997;15:315-23.

22 Brink HR van den, Wijk MJG van, Geertzen RGM, Bijlsma JWJ. Influence of corticosteroid pulse therapy on the serum evels of soluble IL-2 receptor, IL-6 and IL-8 in patients with rheumatoid arthritis. J Rheumatol 1994;21:430-4.

23 Bertouch JV, Roberts-Thompson PJ, Smith MD, Woodruff TG, Brooks PM, Bradley J. Methylprednisolone infusion therapy in rheumatoid arthritis patients. The effect on synovial fluid lymphocyte subsets and inflammatory indices. Arthritis Rheum 1986;29:32-8.

24 Daynes RA, Araneo BA. Contrasting effects of glucocorticoids on the capacity of $\mathrm{T}$ cells to produce the growth faccoids on the capacity of T cells to produce the growth fac-
tors interleukin 2 and interleukin 4 . Eur J Immunol 1989; 19: 2319-25.

25 Arya SK, Wong-Staal F, Gallo RC. Dexamethasone mediated inhibition of human $\mathrm{T}$ cell growth factor and $\gamma$-interferon messenger RNA. J Immunol 1984;133:273-6. 
26 Brinkmann V, Kristofic C. Regulation by corticosteroids of Th1 and Th2 cytokine production in human $\mathrm{CD}^{+}$effector Immunol 1995; 155:3322-8.

27 Tabardel Y, Duchateau J, Schmartz D, Marcecaux G Shahla M, Barvais L, et al. Corticosteroids increase blood interleukin-10 levels during cardiopulmonary bypass in men. Surgery 1996;119:76-80.

28 Youssef PP, Haynes DR, Triantafillou S, Parker A, Gamble JR. Effects of pulse methylprednisolone on inflammatory mediators in peripheral blood, synovial fluid and synovial membrane in rheumatoid arthritis. Arthritis Rheum 1997; 40:1400-8.

29 Rook GAW, Hernandez-Pando R, Lightman SL. Hormones, peripherally activated prohormones and regulation of the Th1/Th2 balance. Immunol Today 1994;15:301-3.

30 Snijdewint FGM, Kapsenberg ML, Wauben-Penris PJJ, Bos JD. Corticosteroids class-dependently inhibit in vitro Th1and Th2-type cytokine production. Immunopharmacology 1995;29:93-101.

31 Crabtree GR, Gillis S, Smith KA, Munck A. Glucocorticoids and immune responses. Arthritis Rheum 1979;22: coids and $1246-56$.

32 Ramirez F, Fowell DJ, Puklavec M, Simmonds S, Mason D. Glucocorticoids promote a Th2 cytokine response by CD4 ${ }^{+} \mathrm{T}$ cells in vitro. J Immunol 1996;156:2406-12.
33 Thompson PW, Silman A, Kirwan JR, Currey HLF. Articular indices of joint inflammation in rheumatoid arthritis. lar indices of joint inflammation
Arthritis Rheum 1987;30:618-23.

34 American Rheumatism Association. Dictionary of the rheumatic diseases. Vol 1. Division ARA functional class. New York: Contact Associates International, 1988.

35 Van der Pouw-Kraan T, Van Kooten C, Rensink I, Aarden L. Interleukin-4 production by human $\mathrm{T}$ cells. Eur $\mathrm{J}$ Immunol 1992;22:1237-41.

36 June CH, Bluestone JA, Nadler LM, Thompson LB. The B7 and CD 28 receptor families. Immunol Today 1994;15: $321-31$

37 Zieg G, Lack G, Harbeck RJ, Gelfland EW, Leung DYM. In vivo effect of glucocorticoids on IgE production. J Allergy Clin Immunol 1994;94:222-30

38 Vacca A, Felli MP, Farina AR, Martinotti S, Maroder M, Screpanti I, et al. Glucocorticoid receptor-mediated suppression of the interleukin 2 gene expression through impairment of the cooperativity between nuclear factor of activated T cells and AP-1 enhancer elements. J Exp Med 1992;175:637-46.

39 Youssef PP, Triantafillou S, Parker A, Coleman M, RobertsThompson PJ, Ahern MJ, et al. Effects of pulse methylprednisolone on cell adhesion molecules in the synovial membrane in rheumatoid arthritis. Arthritis Rheum 1996; 39:1970-9 